\title{
Long non-coding RNA NEAT1 promotes malignant progression of thyroid carcinoma by regulating miRNA-214
}

\author{
JIAN-HUA LI ${ }^{1,4^{*}}$, SU-QIN ZHANG ${ }^{2 *}$, XING-GUANG QIU ${ }^{1}$, SHUI-JUN ZHANG ${ }^{3}$, \\ SHOU-HUA ZHENG ${ }^{1}$ and DAN-HUA ZHANG ${ }^{1}$
}

${ }^{1}$ The Second Thyroid Department, ${ }^{2}$ Department of Pediatrics, ${ }^{3}$ Department of General Surgery, The First Affiliated Hospital of Zhengzhou University; ${ }^{4}$ The Key Laboratory of Digestive Organ Transplantation, Zhengzhou, Henan 450052, P.R. China

Received September 21, 2016; Accepted November 11, 2016

DOI: $10.3892 /$ ijo.2016.3803

\begin{abstract}
The long non-coding RNA nuclear enrich abundant transcript 1 (NEAT1) has been identified to be carcinogenic in various cancers and elevated NEAT1 expression was tightly linked to tumorigenesis and progression. However, the mechanism has not been revealed in progression of thyroid cancer. Tumor xenograft mouse model was established and tumor size was evaluated. Arg-1, NEAT1 and miR-214 expression in CBMs, TAMs, BMDMs and RAW 264.7 cell lines were detected. TPC-1 cells were subjected to si-NEAT1 transfection in vitro for cell viability study. A direct target of miRNA-214 ( $\beta$-catenin) was assessed, cell survival and invasion in TAMs were investigated. NEAT1, Arg-1 was highly expressed and miRNA-214 had lower expression in patients with thyroid cancer. NEAT1 knockout inhibited thyroid cancer cell survival, migration and invasion, along with reduced $\beta$-catenin (a direct target of miRNA-214) protein expression. Furthermore, NEAT1 significantly accelerated thyroid cancer cell growth and metastasis in vitro and increased tumor size in vivo. Upregulation of NEAT1 decreased the expression of miRNA-214, presenting a reciprocal repression correlation. In conclusion, these results suggest that high expression of NEAT1 promoted the onset of thyroid carcinoma. In addition, NEAT1 promoted the malignant progression of thyroid cancer through regulating miRNA-214 expression, which adds to our understanding of the molecular mechanisms in thyroid carcinoma.
\end{abstract}

\section{Introduction}

With the development of modern industry, thyroid cancer is becoming the most common endocrine malignancy, and

Correspondence to: Dr Jian-Hua Li, The Second Thyroid Department, The First Affiliated Hospital of Zhengzhou University, Zhengzhou, Henan 450052, P.R. China

E-mail: jianhualijh@163.com

${ }^{*}$ Contributed equally

Key words: 1ncRNA, NEAT1, thyroid cancer cells, miRNA-214 its incidence has increased by nearly 3-fold during the past several years (1-4). Papillary thyroid cancer (PTC) accounts for $85-90 \%$ of the predominant histological subtypes, and $>90 \%$ of patients have a 10 year survival rate $(5,6)$. Although the overall prognosis is good, $15-30 \%$ PTC patients will have persistence or recurrence and 5-10\% will suffer progressive, distant metastasis, for whom 5 years of survival is only less than half (7). As for these patients, the available adjunctive therapies currently are often of limited benefit (5). Therefore, it is urgent to discover the molecular mechanisms by which PTC is maintained and provide a new focus for the development of PTC treatments.

The mechanisms underlying aggressive PTC continue to be elucidated and may include tumor-mediated immune suppression (8). Nowadays, immunotherapy has gradually become a new therapeutic approach for patients with recurrent or progressive PTC. There are studies showing that the level of immunosuppressive molecules and specific patterns of tumor infiltrating leukocytes (TIL) have predicted tumorigenesis and recurrence in some solid malignancies (9-11). In addition, immunotherapy regimens such as programmed cell death 1 ligand 1 (PD-L1) and IL-2 have induced remarkable durable cancer regressions in patients with metastatic diseases, including lung, prostate, and renal cell cancers $(12,13)$. It is now established that host immune cells can recognize and eliminate malignant cells, but that abnormal antigens present in tumors, neoplastic growths frequently evolve mechanisms to escape immune destruction, including downregulation of antigen recognition, the expression of immune-inhibitory ligands, and the recruitment of suppressor cell populations $(11,14,15)$. In order to effectively treat cancer, immunotherapy could reverse the tumor-driven immune dysfunction, further restore immune responses and bring antigen specific reaction.

Long non-coding RNAs (lncRNAs) are a class of RNAs that do not encode proteins, with length of $>200 \mathrm{nt}$ (16-18). They are widely distributed in a variety of human tissues and play an important role in physical processes, with increasing evidence revealing that they are involved in cell-type feature and diverse cellular events, including epigenetic regulation, gene transcription and mRNA processing (19). LncRNAs are ubiquitous disorders in cancers, especially resulting in aberrant proliferation, migration and invasion, and apoptosis (20), which contribute to the advance of human tumors 
and tumor outcomes (21-23). As a kind of lncRNA, lncRNA nuclear enrich abundant transcript 1 (NEAT1), a 4-kb lncRNA localized to the nucleus (24), serves as a crucial architectural component of a paraspeckle structure (25-27). NEAT1 has been demonstrated to act as a key role in various cancers, including acute promyelocytic leukemia cells (28), prostate cancer (29), breast cancer (30), hepatocellular carcinoma (31), ovarian carcinoma (32) and glioma (33). However, whether NEAT1 is associated with the malignant progression of PTC remains unclear.

MicroRNAs (miRNAs, $22 \mathrm{nt}$ ) are a group of small non-coding RNAs with aberrant expression in various tumors (34). miRNAs, as a major class of well characterized, conserved and endogenous small interfering RNA that regulate gene expression (35). It has been indicated that miRNAs are involved in diverse biological processes, such as cell growth, migration, apoptosis and differentiation through mainly binding to the 3'-untranslated region (3'-UTR) of their target genes $(34,36)$. In addition, miRNAs can function as either oncogenes or tumor suppressor genes via regulation of cell proliferation or cell death (37). miRNA-214 also plays a vital role as a tumor inhibitor by downregulating oncogenes, such as GALNT7, Bcl212 and TFAM in cervical cancer (38-40) and FGF-1 and ARL-2 in colorectal cancer $(41,42)$. However, miRNA-214 is highly expressed in melanoma (43), gastric cancers (44) and ovarian cancer (45), which suggesting that it may function as an carcinogenic gene as well. These results are, however, contradictory as the same miRNA may act as a carcinogen in one cancer type and as a suppressor in another cancer. Therefore, the expression and function of miRNA-214 in PTC need further investigation.

In the present study, we sought to determine the expression and function of NEAT1 and miRNA-214 in thyroid tumor tissue and TPC-1 thyroid cancer cells. We also investigated the interactions among them in the regulation of PTC malignant behavior and the potential molecular pathways involved.

\section{Materials and methods}

Tissue collection. All the samples were collected from patients who had undergone surgery and were diagnosed with thyroid cancer based on pathological evaluation at the First Affiliated Hospital of Zhengzhou University. Informed consent was gathered from patients, and the research method was approved by the Ethics Committee of the First Affiliated Hospital of Zhengzhou University. No local or systemic treatment had been conducted in patients before the operation. All the specimens were immediately snap-frozen and preserved in liquid nitrogen until use in this study.

Cell lines and culture conditions. Human circulating blood monocytes (CBMs) and tumor-associated macrophages (TAMs) were isolated from thyroid cancer patients. Bone marrow derived macrophages (BMDMs) and macrophages (RAW 264.7) were purchased from Shanghai Enzyme Research Biotechnology Co., Ltd. (Shanghai, China). Thyroid cancer cell TPC-1 was purchased from the ScienCell Research Laboratories (Carlsbad, CA, USA). They were maintained in low-glucose Dulbecco's modified Eagle's medium (DMEM-L) (Life Technologies Corp., Carlsbad, CA, USA) containing
$10 \% \mathrm{FBS}$ and $100 \mathrm{U} / \mathrm{ml}$ penicillin and $100 \mu \mathrm{g} / \mathrm{ml}$ streptomycin antibiotics in a humidified atmosphere of $5 \% \mathrm{CO}_{2}$ at $37^{\circ} \mathrm{C}$.

Cell transfection. The NEAT1 knockdown (si-NEAT1) plasmid and the NEAT1 overexpression (Ad-NEAT1) plasmid, as well as the respective non-targeting sequence (negative control, si-control and Ad-GFP) were synthesized by GenePharma Co. (Shanghai, China). Cells were transient transfected through the use of Lipofectamine 2000 transfection reagent (Life Technologies Corp., Shanghai, China) according to the manufacturer's instructions when cells were at 50-70\% confluence. The transfection efficiency was verified by qRT-PCR analysis.

$R N A$ extraction and $q R T-P C R$. Total RNA was extracted from clinical specimens and cells with the TRIzol reagent (Invitrogen, Carlsbad, CA, USA) according to the manufacturer's instructions. A One-Step SYBR Prime Script RT-PCR kit was used for qRT-PCR. cDNA was generated from miRNA with a TaqMan miRNA reverse transcription kit (Applied Biosystems, Foster City, CA, USA). TaqMan Universal Master Mix II was used to perform TaqMan miRNA assays for target genes on the ABI 7500 Fast Real-Time PCR system (Applied Biosystems). GAPDH and U6 were used as endogenous controls, respectively. The relative expression level was calculated using the $2^{-\Delta \Delta \mathrm{Ct}}$ method. The formula and its derivations were obtained from the ABI Prism 7300 sequence detection system user guide. Statistical analysis was performed on the fold-change.

Western blotting. Total proteins were extracted from cells with RIPA buffer containing protease inhibitors (Beyotime Institute of Biotechnology) on ice, and these protein concentrations were quantified by Bradford's method according to the manufacturer's protocol. Samples were then subjected to SDS-PAGE and transferred to PVDF membranes by semidry electroblotting. After non-specific binding was blocked with $5 \%$ nonfat milk at room temperature, membranes were incubated with primary antibodies anti-NEAT1 and anti-ACTB (Santa Cruz Biotechnology, Inc., Santa Cruz, CA, USA). Then, membranes were incubated with HRP-conjugated secondary antibodies (Santa Cruz Biotechnology, Inc.) at room temperature. Bands detected using the enhanced chemiluminescence kit (ECL kit; Santa Cruz Biotechnology, Inc.) and analyzed by densitometry (Image Lab; Bio-Rad Laboratories, Hercules, CA, USA). ACTB was used as an internal control.

Cell survival and viability assay. After transfection efficacy was confirmed, cells were dissociated with Accutase ${ }^{\circledR}$ Cell Dissociation buffer (Life Technologies Corp.) resuspended and seeded in 96-well micro-hole plates at $1.0 \times 10^{3}$ cells/ well. Volume of $10 \mu \mathrm{l} \mathrm{CCK-8}$ was added to each well at the time of harvest, according to the manufacturer's instructions. The plate was incubated for $2 \mathrm{~h}$ at $37^{\circ} \mathrm{C}$ and then recorded cell survival and viability by measuring the absorbance of the converted dye at $450 \mathrm{~nm}$ on a SpectraMax M5 microplate reader (Molecular Devices, Sunnyvale, CA, USA).

Cell migration and invasion assay. To measure cell migration, 8-mm pore size culture inserts (Transwell; Costar, Cambridge, UK) were placed into the 24-well culture plates, separating 

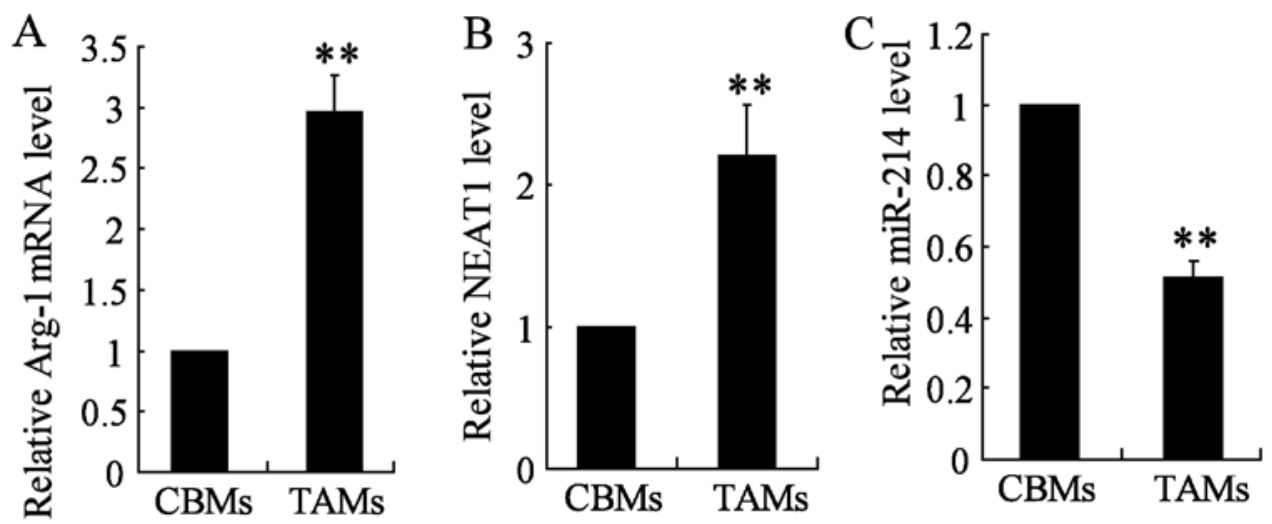

Figure 1. Relative NEAT1, Arg-1 and miRNA-214 expression in circulating blood monocytes (CBMs) and tumor-associated macrophages (TAMs). (A) Relative expression of Arg-1. (B) Relative expression of NEAT1. (C) Relative expression of miRNA-214. The expression of NEAT1, Arg-1 and miRNA-214 was examined by qRT-PCR. ${ }^{* *} \mathrm{P}<0.01$. Means \pm SD are shown. Statistical analysis was conducted using Student's t-test.

the upper and the lower chambers. In the lower chamber, DMEM containing $10 \%$ FBS was added. Serum-free medium containing $5 \times 10^{4}$ cells were placed to the upper chamber for migration and invasion assay. After incubation at $37^{\circ} \mathrm{C}$ for $48 \mathrm{~h}$, the cells on the upper membrane surface were scraped off. The cells on the lower side of the member were fixed and then stained with $0.1 \%$ crystal violet. The number of cells that had migrated through the pores was quantified by counting 10 independent visual fields under the microscope for statistics. At magnification x20. Each experiment was performed at least 3 times.

RNA pull-down assay. NEAT1 and its antisense RNA were in vitro transcribed and biotin-labeled using a biotin RNA labeling mix and T7/SP6 RNA polymerase, treated with RNase-free DNase I and purified using an RNeasy mini kit (Qiagen, Valencia, CA, USA) to detect Argonaute 2 (Ago2) expression by western blotting. All these procedures were according to the manufacturer's protocol. One milligram of protein from cell extracts was mixed with 50 pmol biotin labeled RNA, incubated with streptavidin-agarose beads, and washed 3 times with $\mathrm{NaCl} / \mathrm{Pi}$ at room temperature. The retrieved proteins were detected using a standard western blotting technique.

Tumor xenografts. Four-week-old nude C57BL/6 mice were purchased from Henan Research Center of Laboratory Animals (Zhengzhou, China). These mice were given free access to sterile food and water during the experiment process. All animal experiments with nude mice were performed strictly in accordance with a protocol approved by Henan Research Center of Laboratory Animal. To establish thyroid cancer xenograft model. The mice were subcutaneously injected with $5 \times 10^{4}$ TPC- 1 cells ( $n=6$ in each group). After 8 days of transplantation, the transplanted nude mice were divided into two groups: si-control, and si-NEAT1. Si-control or si-NEAT1 was directly injected into the implanted tumors per mouse every 4 days for 4 times. The subcutaneous tumor-bearing mice were sacrificed 2 weeks after injection. The tumor volume was calculated by the formula: volume $\left(\mathrm{mm}^{3}\right)=$ length $\mathrm{x}$ width ${ }^{2} / 2$.

Statistical analysis. Data are presented as the mean \pm standard deviation (SD). All experimental results were statistically analyzed with Student's t-test or one-way analysis of variance (ANOVA). All statistical analyses were performed with SPSS 18.0 statistical software. A value of $\mathrm{P}<0.05$ was considered to indicate statistically significant difference.

\section{Results}

NEAT1 is upregulated while miR-214 is downregulated in thyroid cancer cell TAMs. As previously reported, NEAT1 was upregulated in glioblastoma tissues (46). Similarly, we found NEAT1 was upregulated in TAM thyroid cancer cell line TAMs compared with CBMs (Fig. 1B). In addition, quantitative real-time PCR (qRT-PCR) was conducted to determine the expression of Arg-1 and miR-214 in the two cell types TAM and CBM. Arg-1 expression was significantly upregulated in TAM cells, however, miR-214 expression was significantly lower in TAM cell lines as compared with those of CBMs (Fig. 1A and C). These results suggested that NEAT1 promotes the occurrence of tumor in TAMs, while miR-214 functions as a tumor suppressor.

NEAT1 is upregulated while miR-214 is downregulated in $B M D M s$ treated with $I L-4$. To further explore the oncogenic properties and roles of NEAT1 on thyroid cancer in vitro, we established thyroid cancer cell lines (BMDMs treated with $20 \mathrm{ng} / \mathrm{ml} \mathrm{IL-4)}$, and detected the mRNA expression of Arg-1, NEAT1 and miR-214 genes at 3, 6 and $12 \mathrm{~h}$, respectively. In this study, we found that the relative Arg-1 mRNA level was significantly increased after $12 \mathrm{~h}$ of treatment in thyroid cancer cell lines (Fig. 2A). Moreover, qRT-PCR analysis for the expression of NEAT1 showed that NEAT1 was obviously increased in BMDM cells at 3, 6 and $12 \mathrm{~h}$ (Fig. 2B). On the contrary, miR-214 gene expression was significantly decreased with 6 and $12 \mathrm{~h}$ treatment (Fig. 2C). The change of the above three parameters all showed a time-dependent manner. These data demonstrate that the upregulation of NEAT1 may play important roles on thyroid cancer development and progression.

Transfection with si-NEATI/Ad-NEATI attenuates/increases IL-4 induced Arg-1 expression in BMDMs and RAW 264.7 cells. The expression of Arg-1 was assessed by qRT-PCR. As mentioned above, NEAT1 expression was upregulated under 

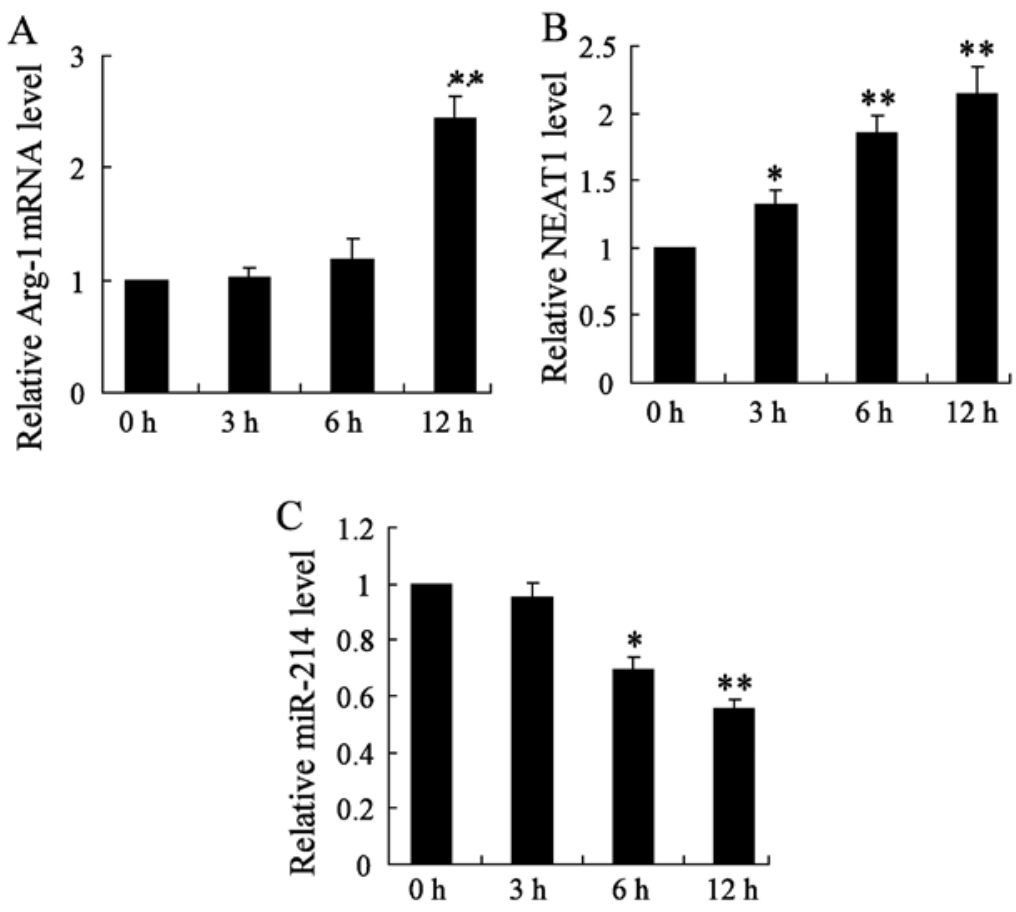

Figure 2. Relative NEAT1, Arg-1 and miRNA-214 expression in BMDMs treated with $20 \mathrm{ng} / \mathrm{ml}$ IL-4 at different time points. (A) Relative expression of Arg-1. (B) Relative expression of NEAT1. (C) Relative expression of miRNA-214. The expression of NEAT1, Arg-1 and miRNA-214 was examined by qRT-PCR. ${ }^{*} \mathrm{P}<0.05$ and ${ }^{* *} \mathrm{P}<0.01$. Means $\pm \mathrm{SD}$ are shown. Statistical analysis was conducted using Student's t-test.
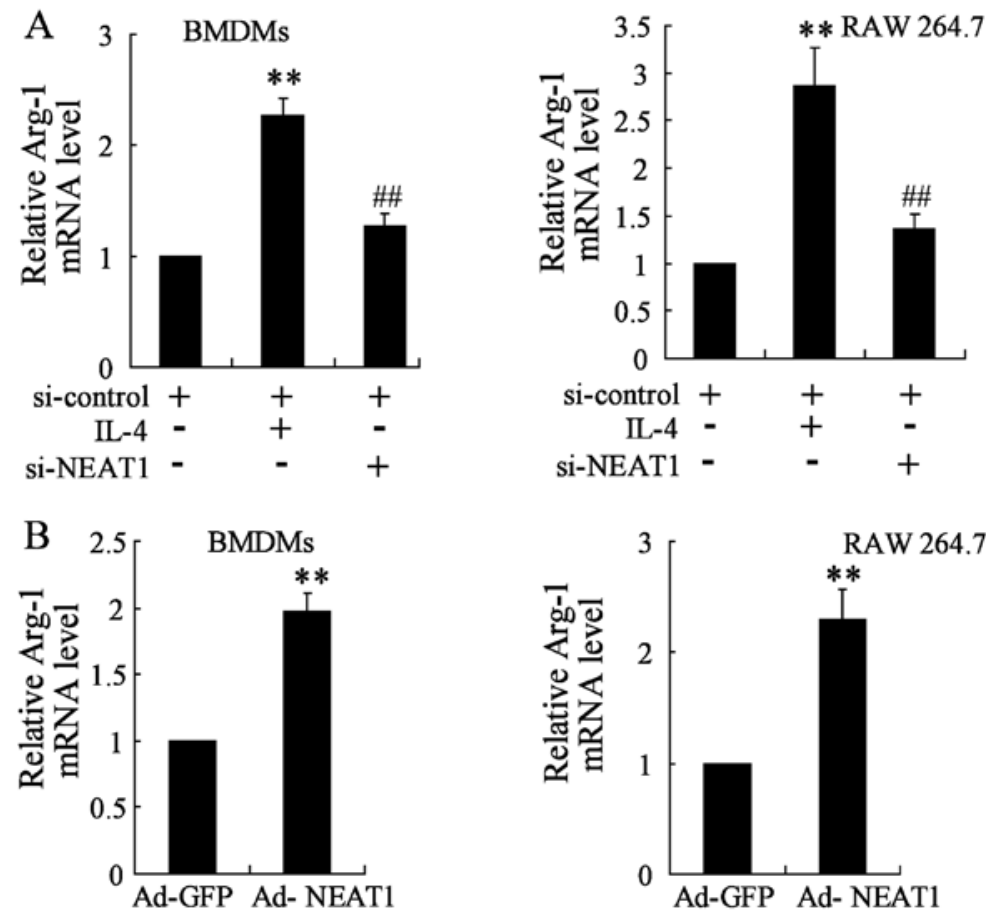

Figure 3. Relative Arg-1 expression in BMDMs and RAW 264.7 treated with $20 \mathrm{ng} / \mathrm{ml}$ IL-4 and si-NEAT1/Ad-NEAT1. (A) Relative expression of Arg-1 in treated BMDMs and RAW 264.7 cell lines transfected with si-NEAT1. (B) Relative expression of Arg-1 in treated BMDMs and RAW 264.7 cell lines transfected with Ad-NEAT1. The expression of Arg-1 was examined by qRT-PCR. ${ }^{* *} \mathrm{P}<0.01$ compared with si-control group; ${ }^{\# \#} \mathrm{P}<0.01$ compared with si-control + IL-4 group. Means \pm SD are shown. Statistical analysis was conducted using Student's t-test.

IL-4 treatment, enforced NEAT1 silence was firstly performed and analyzed by transfecting si-NEAT1 that targets NEAT1 transcript into BMDMs and RAW 264.7 cells. Analysis for Arg-1 gene level demonstrated to be strongly attenuated in NEAT1 silencing thyroid cancer cell lines close to a basal expression level (Fig. 3A). Moreover, thyroid cancer cell lines were transfected with Ad-NEAT1 to overexpress NEAT1. The expression of Arg-1 was markedly promoted in BMDMs and RAW 264.7 cells transfected with Ad-NEAT1 compared to that in the control group (Fig. 3B). 

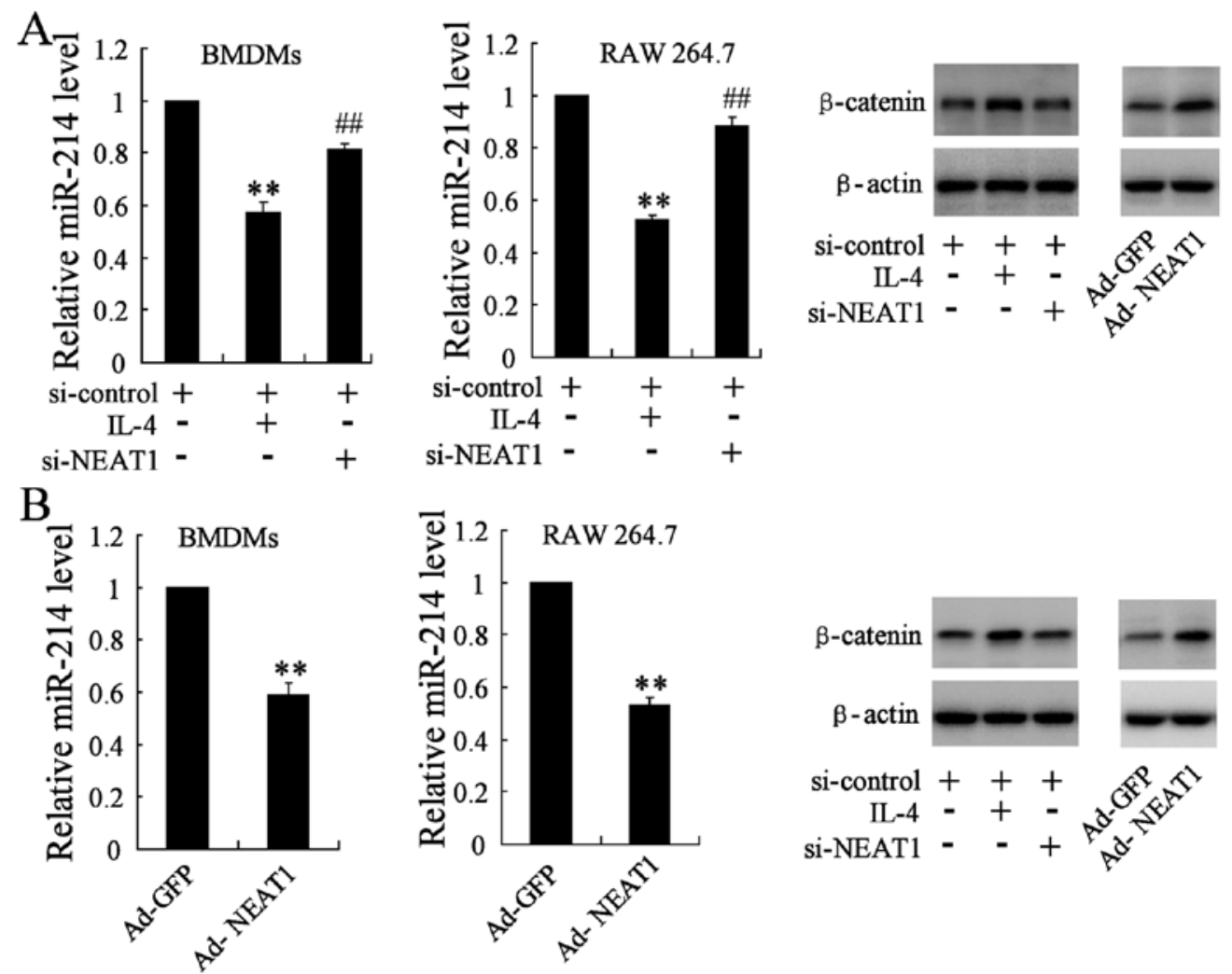

Figure 4. The expression of miRNA-214 and $\beta$-catenin in BMDMs and RAW 264.7 treated with $20 \mathrm{ng} / \mathrm{ml}$ IL-4 and si-NEAT1/Ad-NEAT1. (A) The expression of miRNA-214 and $\beta$-catenin in treated BMDMs and RAW 264.7 cell lines transfected with si-NEAT1. (B) The expression of miRNA-214 and $\beta$-catenin in treated BMDMs and RAW 264.7 cell lines transfected with Ad-NEAT1. The expression of miRNA-214 and $\beta$-catenin was examined by qRT-PCR and western blotting method, respectively. GAPDH and $\beta$-actin was considered as internal reference. ${ }^{* *} \mathrm{P}<0.01$ compared with si-control group; ${ }^{\# \prime} \mathrm{P}<0.01$ compared with si-control + IL-4 group. Means \pm SD are shown. Statistical analysis was conducted using Student's t-test.

Transfection with si-NEAT1/Ad-NEAT1 reverses/decreases IL-4 induced miR-214 and $\beta$-catenin expression in BMDMs and RAW 264.7 cells. Similarly, in order to determine the effect of si-NEAT1/Ad-NEAT1 on the expression of miR-214 and $\beta$-catenin, we divided cells into three groups: si-control group (transfected with si-control plasmid), si-NEAT1 group (transfected with si-control plasmid and the si-NEAT1 plasmid) and the IL-4 group (transfected with si-control plasmid and $20 \mathrm{ng} / \mathrm{ml}$ IL-4). The qRT-PCR assay indicated that miR-214 gene level was reduced in IL-4 group, while it was obviously reversed in NEAT1 silencing BMDMs and RAW 264.7 cells. $\beta$-catenin, as the direct target molecule of miR-214, was also determined by western blotting. The protein level of $\beta$-catenin was remarkably downregulated in BMDMs and RAW 264.7 cells transfected with si-NEAT1 when compared with the IL-4 group (Fig. 4A). BMDMs and RAW 264.7 were simultaneously transfected with the Ad-NEAT1 plasmid, the change of miR-214 level and $\beta$-catenin expression was analyzed accordingly, opposite results were observed in treated groups (Fig. 4B).

NEAT1 is a direct target of miR-214 in thyroid cancer cell lines. Increasing evidence has demonstrated that lncRNAs could act as a molecular sponge or a competition endogenous RNA (ceRNA) in regulating the accumulation of miRNA and in turn affecting its biological functions. Using a bioinformatics database (StarBase), we determined that NEAT1 harbors seven putative binding sites for miR-214 (Fig. 5A).
Furthermore, an RNA pull-down experiment was conducted to determine whether NEAT1 and Ago2 were in the expected RNA-induced silencing complex (RISC). A significant enrichment was found of Ago2 in the presence of NEAT1 compared with antisense RNA (negative control) (Fig. 5B). In addition, the miR-214 gene expression was remarkably promoted in NEAT1 interfered group compared with antisense RNA group (Fig. 5C). These results revealed miR-214 could directly bind to NEAT1 at the miRNA recognition site.

Knockdown of NEAT1 impairs the malignant progression of thyroid papillary carcinoma-1. To investigate whether the NEAT1 silencing can block cell survival and invasion, we used two different approaches to evaluate the role of NEAT1 on TPC-1 cell malignant progression. The CCK- 8 assay indicated that TPC-1 survival was lower in the si-NEAT1 group than in the si-control group (Fig. 6A). We also evaluated cancer cell migration and invasion through Transwell assays. The migration and invasion of TPC-1 were also significantly impeded in the NEAT1-knockdown group compared to the si-control group (Fig. 6B). Moreover, the inhibition of NEAT1 had no significant effect on the cell viability of TPC-1 cells between si-NEAT1 and si-control groups (Fig. 7). These results indicated that NEAT1 may act as a oncogene in TPC-1 cells.

Knockdown of NEATl inhibits thyroid tumor growth in vivo. To verify the effects of NEAT1 on tumorigenesis in vivo, TPC-1 cells or appropriate control cells were subcutaneously 

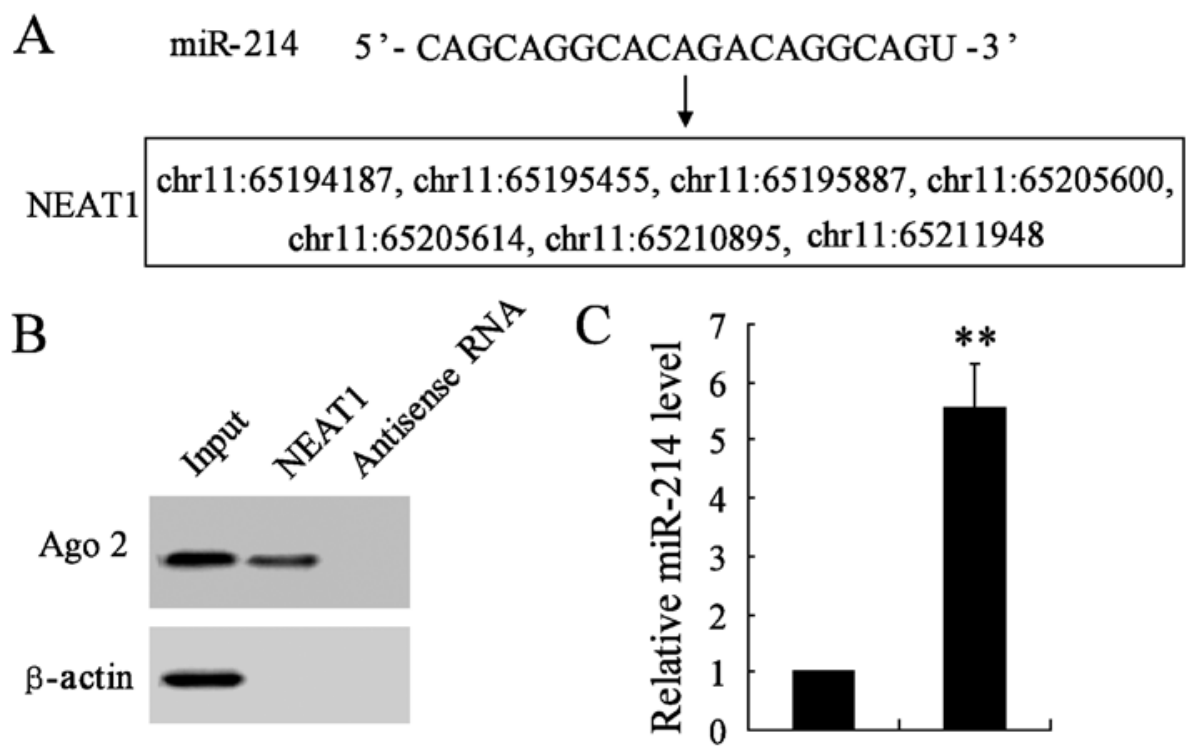

Antisense RNA NEAT1

Figure 5. NEAT1 is a direct target of miRNA-214. (A) Sequence alignment of miRNA-214 with the putative binding sites within NEAT1. (B) A pull-down assay was performed as described in Materials and methods. NEAT1 or antisense RNA was incubated with cell extracts, and the Ago2 protein was assayed by western blotting. $\beta$-actin was used as the control. (C) qRT-PCR detection interference miR-214. ${ }^{* *} \mathrm{P}<0.01$. Means \pm SD are shown. Statistical analysis was conducted using Student's t-test.
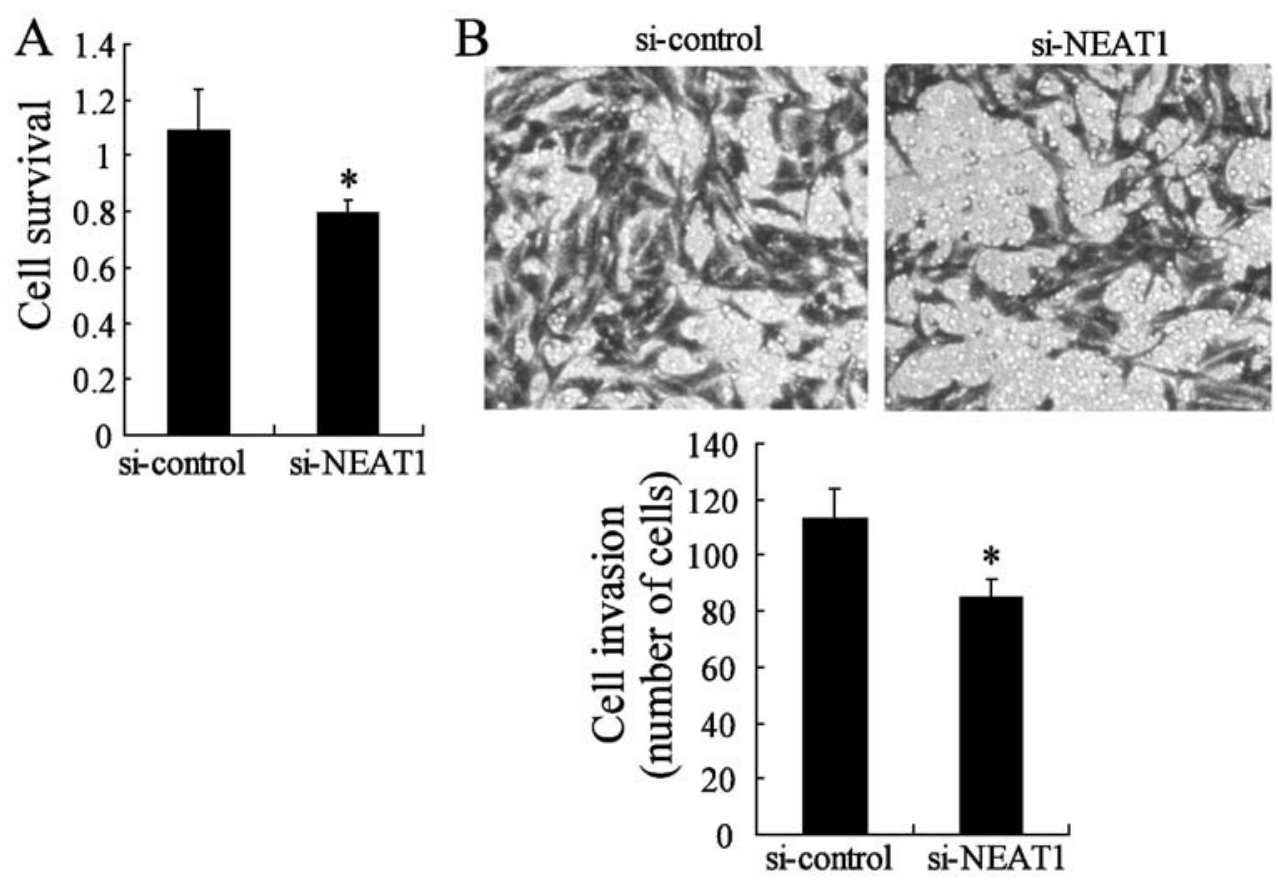

Figure 6. Transfection with si-NEAT1 inhibits thyroid cancer (TAMs) cell survival, migration and invasion. (A) The CCK-8 assay was employed to determine the effect of si-NEAT1 on TAM cell survival. (B) Quantification of TAM cell migration and invasion according to si-NEAT1 expression. Representative images and accompanying statistical plots are presented. Data are presented as the mean $\pm \mathrm{SD}$. ${ }^{*} \mathrm{P}<0.05$ compared with si-control group. Scale bars, $20 \mu \mathrm{m}$.

injected into nude mice. Si-NEAT1 was directly injected into the implanted tumor at the 8th day after injection every 4 days. Knockout of NEAT1 significantly decreased tumor size and tumor growth in vivo compared with si-control group (Fig. 8A). Using qRT-PCR analysis, we confirmed the NEAT1 knockout in the xenograft tumors generated from thyroid cancer TAM cells (Fig. 8B). Taken together, these results demonstrated that NEAT1 plays a crucial role in thyroid cancer TAM cell progression.

\section{Discussion}

Previous studies have explored the functional roles of lncRNAs $(18,47,48)$, and indicated new insights into the underlying molecular mechanisms by which lncRNAs take effect in various human cancers (49-51). However, the mechanisms of NEAT1 in thyroid cancer have not been thoroughly revealed. In the present study, we provided new evidence that highly expressed NEAT1 in thyroid cancer cells acted as an oncogenic 


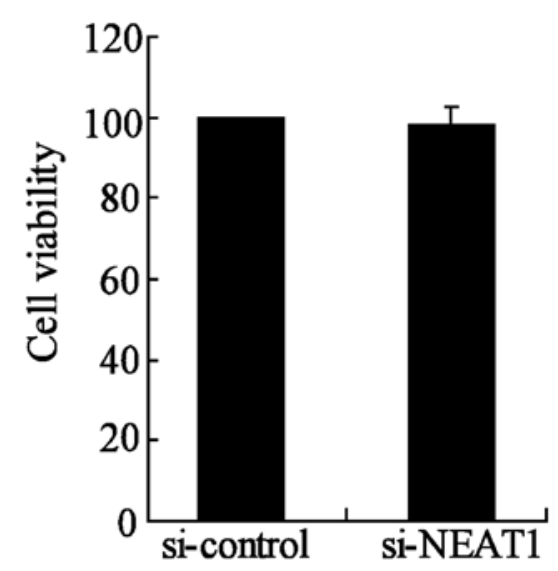

Figure 7. Transfection with si-NEAT1 does not influence thyroid papillary cancer (TPC-1) cell viability. The CCK-8 assay was employed to determine the effect of si-NEAT1 on TPC-1 cell viability. Data are presented as the mean \pm SD. ${ }^{*} \mathrm{P}<0.05$ compared with si-control group.

biomarker. NEAT1 was found to be a direct target of miR-214 and there was a negative correlation between them. NEAT1 served as an oncogene to promote tumor process partiallu due to its ability to depress the expression of miR-214. Hence, our findings may help to improve the literature supporting the importance of lncRNA species in cancer treatment.

In this study, we demonstrated that NEAT1 was upregulated in thyroid cancer cells. NEAT1 inhibition impaired the malignant process of thyroid papillary carcinoma-1 and attenuated $\beta$-catenin expression. On the contrary, miR-214 expression was downregulated in thyroid cancer TAMs, BMDMs and RAW 264.7 cells. Moreover, miR-214 was found to bind to NEAT1 in a specific manner, and showed a reciprocal repression correlation. $\beta$-catenin was considered to be a direct target of miR-214 and was involved in the NEAT1-induced malignant behavior of thyroid cancer. Collectively, our observations indicated NEAT1 may serve as an oncogene and play an important role in thyroid cancer initiation, development and progression.

Emerging evidence presented that lncRNAs are abnormally expressed in various cancers (46). Because they are involved in the occurrence and progression of cancer, lncRNAs could be used as diagnostic or prognostic markers and potential therapeutic targets. Previous study indicated that NEAT1 was upregulated in glioma, and promoted cell proliferation, migration and invasion while inhibiting apoptosis in glioma cell lines (33). Similar findings were observed in this study, knockout NEAT1 suppressed the malignant progression of thyroid papillary carcinoma- 1 cells. In addition, we also further determined the expression of $\beta$-catenin and found that NEAT1 knockout significantly reduced $\beta$-catenin level in thyroid cancer cells. However, whether $\beta$-catenin is also involved in the NEAT1-induced enhancement of thyroid cancer progression needs to be further investigated.

So far, NEAT1 has been considered to act as a cancer inducing gene, but the deep mechanism by which NEAT1-regulated gene expression remains to be clarified (52). It has been demonstrated that NEAT1 played an important role in numerous biological processes, including cellular differentiation and stress response through paraspeckles pathway (53). Evaluation of the effect of NEAT1 on transcriptional regulation by sequestering SFPQ from the RNA-specific adenosine deaminase, RNA specific B2 (ADARB2) gene in response to proteasome inhibition effect has been reported (54). In the present study, we intended to discover another underlying molecular mechanism of NEAT1 on thyroid cancer progression, that is, functioning as 'molecular sponges' to regulate miRNAs. A previous study proved that in a variety of cell processes, lncRNAs played a vital role through acting as ceRNAs to mediate the miRNAs (17). Various lncRNAs have been investigated in cancer research, including lncRNA GAS5 (54) and CCAT1 (55). In this study, we evaluated the effect of NEAT1 on thyroid cancer cells and discovered that NEAT1 participated in the development of ceRNA regulatory networks and acted as an endogenous miRNA sponge, binding to miR-214 and regulating its function. There are studies indicating miR-214 tumor inhibitory effect in various acute or chronic diseases. Study of Xiong et al found that downregulation of miR-214 induced G1 cell cycle arrest in gastric cancer cells by upregulating PTEN (56). Yang et al reported that miR-214 induces cell survival and cisplatin resistance through targeting the 3'-UTR of PTEN (45). miR-214 was downregulated in cervical cancer tissue and could negatively regulate HeLa cell growth $(38,57)$, while its role on thyroid cancer cells have not been investigated. In this experiment, we found that miR-214 expresson was low in thyroid cancer cells.
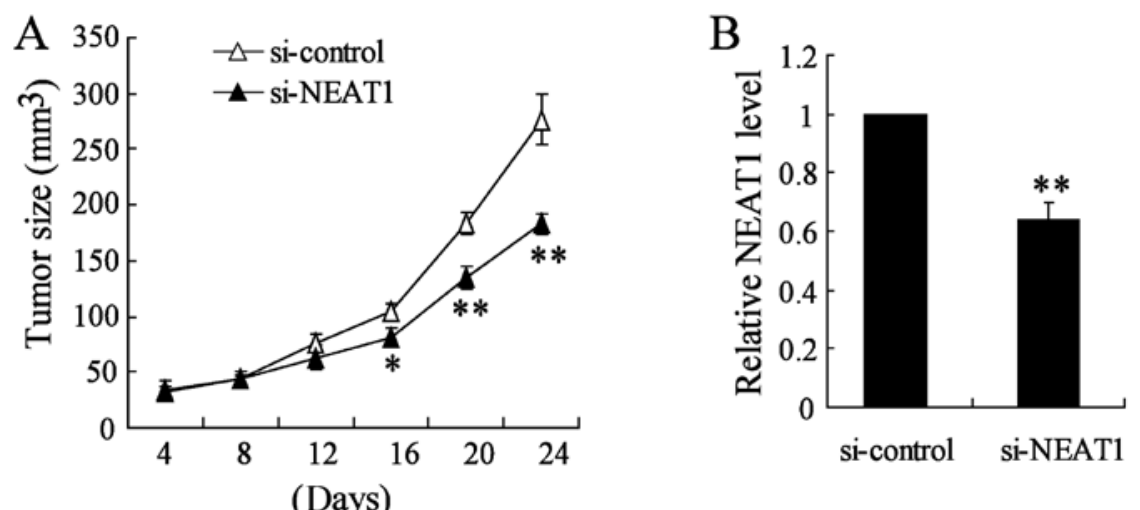

Figure 8. NEAT1 silencing impairs the malignant progression of thyroid carcinoma in vivo. (A) Tumor size of subcutaneous implantation models of TPC-1 cells. (B) Relative NEAT1 expression in tumors isolated from si-control and si-NEAT1 groups. ${ }^{* *} \mathrm{P}<0.01$. Means \pm SD are shown. Statistical analysis was conducted using Student's t-test. 
In addition, the expression of NEAT1 and miR-214 showed a significantly negative correlation in thyroid cancer cell lines. Knockout of NEAT1 remarkably increased miR-214 expression, while overexpression of NEAT1 decreased its expression. Moreover, a pull-down assay showed NEAT1 could pull-down miR-214.

In conclusion, our results indicate that highly expressed NEAT1 is an oncogenic lncRNA that promotes tumorigenesis and progression of thyroid cancer through regulating the expression of miR-214. The significance of the correlation among NEAT1, miR-214 and thyroid cancer was highlighted for the first time. Thus, NEAT1 could be a useful marker and the combination of NEAT1/miR-214 may be a promising option for the treatment of human thyroid cancer.

\section{Acknowledgements}

We would like to thank all the members participated in the research. This study was supported by Henan Provincial Science and Technology Department of Foundation and Frontier Technology Research Fund (No. 162300410114).

\section{References}

1. Amphlett B, Lawson Z, Abdulrahman GO Jr, White C, Bailey R, Premawardhana LD and Okosieme OE: Recent trends in the incidence, geographical distribution, and survival from thyroid cancer in Wales, 1985-2010. Thyroid 23: 1470-1478, 2013.

2. Chen AY, Jemal A and Ward EM: Increasing incidence of differentiated thyroid cancer in the United States, 1988-2005. Cancer 115: 3801-3807, 2009.

3. Davies L and Welch HG: Increasing incidence of thyroid cancer in the United States, 1973-2002. JAMA 295: 2164-2167, 2006.

4. Siegel R, Naishadham D and Jemal A: Cancer statistics, 2013. CA Cancer J Clin 63: 11-30, 2013.

5. Cooper DS, Doherty GM, Haugen BR, Kloos RT, Lee SL, Mandel SJ, Mazzaferri EL, McIver B, Pacini F, Schlumberger M, et al; American Thyroid Association (ATA) Guidelines Taskforce on Thyroid Nodules and Differentiated Thyroid Cancer: Revised American Thyroid Association management guidelines for patients with thyroid nodules and differentiated thyroid cancer. Thyroid 19: 1167-1214, 2009.

6. Hay ID, Thompson GB, Grant CS, Bergstralh EJ, Dvorak CE, Gorman CA, Maurer MS, McIver B, Mullan BP, Oberg AL, et al: Papillary thyroid carcinoma managed at the Mayo Clinic during six decades (1940-1999): Temporal trends in initial therapy and long-term outcome in 2444 consecutively treated patients. World J Surg 26: 879-885, 2002.

7. Grebe SK and Hay ID: Thyroid cancer nodal metastases: Biologic significance and therapeutic considerations. Surg Oncol Clin N Am 5: 43-63, 1996.

8. Angell TE, Lechner MG, Jang JK, Correa AJ, LoPresti JS and Epstein AL: BRAF V600E in papillary thyroid carcinoma is associated with increased programmed death ligand 1 expression and suppressive immune cell infiltration. Thyroid 24: 1385-1393, 2014

9. Galon J, Pagès F, Marincola FM, Thurin M, Trinchieri G Fox BA, Gajewski TF and Ascierto PA: The immune score as a new possible approach for the classification of cancer. J Transl Med 10: 1, 2012

10. Russell S, Angell T, Lechner M, Liebertz D, Correa A, Sinha U, Kokot $\mathrm{N}$ and Epstein $\mathrm{A}$ : Immune cell infiltration patterns and survival in head and neck squamous cell carcinoma. Head Neck Oncol 5: 24, 2013.

11. Stewart TJ and Abrams SI: How tumours escape mass destruction. Oncogene 27: 5894-5903, 2008.

12. McDermott DF: Improving the therapeutic index of IL-2. Clin Adv Hematol Oncol 8: 862-864, 2010.

13. Shablak A, Sikand K, Shanks JH, Thistlethwaite F, Spencer-Shaw A and Hawkins RE: High-dose interleukin-2 can produce a high rate of response and durable remissions in appropriately selected patients with metastatic renal cancer. J Immunother 34: 107-112, 2011.
14. Lechner MG, Russell SM, Bass RS and Epstein AL: Chemokines, costimulatory molecules and fusion proteins for the immunotherapy of solid tumors. Immunotherapy 3: 1317-1340, 2011.

15. Lechner MG, Karimi SS, Barry-Holson K, Angell TE, Murphy KA, Church CH, Ohlfest JR, Hu P and Epstein AL: Immunogenicity of murine solid tumor models as a defining feature of in vivo behavior and response to immunotherapy. J Immunother 36: 477-489, 2013.

16. Liz $\mathrm{J}$ and Esteller M: IncRNAs and microRNAs with a role in cancer development. Biochim Biophys Acta 1859: 169-176, 2016.

17. Mercer TR, Dinger ME and Mattick JS: Long non-coding RNAs: Insights into functions. Nat Rev Genet 10: 155-159, 2009.

18. Ørom UA, Derrien T, Beringer M, Gumireddy K, Gardini A, Bussotti G, Lai F, Zytnicki M, Notredame C, Huang Q, et al: Long noncoding RNAs with enhancer-like function in human cells. Cell 143: 46-58, 2010.

19. Wang J, Liu X, Wu H, Ni P, Gu Z, Qiao Y, Chen N, Sun F and Fan Q: CREB up-regulates long non-coding RNA, HULC expression through interaction with microRNA-372 in liver cancer. Nucleic Acids Res 38: 5366-5383, 2010.

20. Zhao X, Wang P, Liu J, Zheng J, Liu Y, Chen J and Xue Y: Gas5 exerts tumor-suppressive functions in human glioma cells by targeting miR-222. Mol Ther 23: 1899-1911, 2015.

21. Tsai MC, Manor O, Wan Y, Mosammaparast N, Wang JK, Lan F, Shi Y, Segal E and Chang HY: Long noncoding RNA as modular scaffold of histone modification complexes. Science 329: 689-693, 2010.

22. Wang KC and Chang HY: Molecular mechanisms of long noncoding RNAs. Mol Cell 43: 904-914, 2011.

23. Yuan JH, Yang F, Wang F, Ma JZ, Guo YJ, Tao QF, Liu F, Pan W Wang TT, Zhou CC, et al: A long noncoding RNA activated by TGF- $\beta$ promotes the invasion-metastasis cascade in hepatocellular carcinoma. Cancer Cell 25: 666-681, 2014.

24. Clemson CM, Hutchinson JN, Sara SA, Ensminger AW, Fox AH, Chess A and Lawrence JB: An architectural role for a nuclear noncoding RNA: NEAT1 RNA is essential for the structure of paraspeckles. Mol Cell 33: 717-726, 2009.

25. Chen LL and Carmichael GG: Altered nuclear retention of mRNAs containing inverted repeats in human embryonic stem cells: Functional role of a nuclear noncoding RNA. Mol Cell 35: 467-478, 2009.

26. Sasaki YT, Ideue T, Sano M, Mituyama T and Hirose T: MENepsilon/beta noncoding RNAs are essential for structural integrity of nuclear paraspeckles. Proc Natl Acad Sci USA 106: 2525-2530, 2009.

27. Sunwoo H, Dinger ME, Wilusz JE, Amaral PP, Mattick JS and Spector DL: MEN epsilon/beta nuclear-retained non-coding RNAs are up-regulated upon muscle differentiation and are essential components of paraspeckles. Genome Res 19: 347-359, 2009.

28. Zeng C, Xu Y, Xu L, Yu X, Cheng J, Yang L, Chen S and Li Y: Inhibition of long non-coding RNA NEAT1 impairs myeloid differentiation in acute promyelocytic leukemia cells. BMC Cancer 14: 693, 2014.

29. Chakravarty D, Sboner A, Nair SS, Giannopoulou E, Li R, Hennig S, Mosquera JM, Pauwels J, Park K, Kossai M, et al: The oestrogen receptor alpha-regulated lncRNA NEAT1 is a critical modulator of prostate cancer. Nat Commun 5: 5383-5383, 2014.

30. Choudhry H, Albukhari A, Morotti M, Haider S, Moralli D, Smythies J, Schödel J, Green CM, Camps C, Buffa F, et al: Tumor hypoxia induces nuclear paraspeckle formation through HIF-2 $\alpha$ dependent transcriptional activation of NEAT1 leading to cancer cell survival. Oncogene 34: 4546, 2015.

31. Guo S, Chen W, Luo Y, Ren F, Zhong T, Rong M, Dang Y, Feng Z and Chen G: Clinical implication of long non-coding RNA NEAT1 expression in hepatocellular carcinoma patients. Int J Clin Exp Pathol 8: 5395-5402, 2015.

32. Kim YS, Hwan JD, Bae S, Bae DH and Shick WA: Identification of differentially expressed genes using an annealing control primer system in stage III serous ovarian carcinoma. BMC Cancer 10: $576,2010$.

33. Li Z, Liu YH, Diao HY, Ma J and Yao YL: Long noncoding RNA NEAT1 promotes glioma pathogenesis by regulating miR-449b-5p/c-Met axis. Tumour Biol 37: 673-683, 2016.

34. Frixa T, Donzelli S and Blandino G: Oncogenic MicroRNAs: key players in malignant transformation. Cancers (Basel) 7: 2466-2485, 2015.

35. Huntzinger $E$ and Izaurralde $E$ : Gene silencing by microRNAs: Contributions of translational repression and mRNA decay. Nat Rev Genet 12: 99-110, 2011. 
36. Wang P, Liu YH, Yao YL, Li Z, Li ZQ, Ma J and Xue YX: Long non-coding RNA CASC2 suppresses malignancy in human gliomas by miR-21. Cell Signal 27: 275-282, 2015.

37. Mardente S, Mari E, Massimi I, Fico F, Faggioni A, Pulcinelli F, Antonaci A and Zicari A: HMGB1-induced cross talk between PTEN and miRs 221/222 in thyroid cancer. Biomed Res Int 2015: 512027, 2015.

38. Yang Z, Chen S, Luan X, Li Y, Liu M, Li X, Liu T and Tang H: MicroRNA-214 is aberrantly expressed in cervical cancers and inhibits the growth of HeLa cells. IUBMB Life 61: 1075-1082, 2009.

39. Wang F, Liu M, Li X and Tang H: MiR-214 reduces cell survival and enhances cisplatin-induced cytotoxicity via down-regulation of Bcl212 in cervical cancer cells. FEBS Lett 587: 488-495, 2013.

40. Wen Z, Lei Z, Ma JA, Li XZ, Zheng XN and Deng XW: The inhibitory role of miR-214 in cervical cancer cells through directly targeting mitochondrial transcription factor A (TFAM). Eur J Gynaecol Oncol 35: 676-682, 2014.

41. Chen DL, Wang ZQ, Zeng ZL, Wu WJ, Zhang DS, Luo HY, Wang F, Qiu MZ, Wang DS, Ren C, et al: Identification of MicroRNA-214 as a negative regulator of colorectal cancer liver metastasis by way of regulation of fibroblast growth factor receptor 1 expression. Hepatology 60: 598-609, 2014.

42. Long LM, He BF, Huang GQ, Guo YH, Liu YS and Huo JR: microRNA-214 functions as a tumor suppressor in human colon cancer via the suppression of ADP-ribosylation factor-like protein 2. Oncol Lett 9: 645-650, 2015.

43. Penna E, Orso F, Cimino D, Vercellino I, Grassi E, Quaglino E, Turco E and Taverna D: miR-214 coordinates melanoma progression by upregulating ALCAM through TFAP2 and miR-148b downmodulation. Cancer Res 73: 4098-4111, 2013

44. Yang TS, Yang XH, Wang XD, Wang YL, Zhou B and Song ZS: MiR-214 regulate gastric cancer cell proliferation, migration and invasion by targeting PTEN. Cancer Cell Int 13: 68, 2013.

45. Yang H, Kong W, He L, Zhao JJ, O'Donnell JD, Wang J, Wenham RM, Coppola D, Kruk PA, Nicosia SV and Cheng JQ: MicroRNA expression profiling in human ovarian cancer: miR-214 induces cell survival and cisplatin resistance by targeting PTEN. Cancer Res 68: 425-433, 2008.

46. Gong W, Zheng J, Liu X, Ma J, Liu Y and Xue Y: Knockdown of NEAT1 restrained the malignant progression of glioma stem cells by activating microRNA let-7e. Oncotarget: Aug 19, 2016 (Epub ahead of print)
47. Geisler S,Lojek L, Khalil AM, Baker KE and Coller J: Decapping of long noncoding RNAs regulates inducible genes. Mol Cell 45: 279-291, 2012.

48. Huarte M, Guttman M, Feldser D, Garber M, Koziol MJ, Kenzelmann-Broz D, Khalil AM, Zuk O, Amit I, Rabani M, et al: A large intergenic noncoding RNA induced by p53 mediates global gene repression in the p53 response. Cell 142: 409-419, 2010.

49. Barnhill LM, Williams RT, Cohen O, Kim Y, Batova A, Mielke JA, Messer K, Pu M, Bao L, Yu AL, et al: High expression of CAI2, a 9p21-embedded long noncoding RNA, contributes to advanced-stage neuroblastoma. Cancer Res 74: 3753-3763, 2014.

50. Nie FQ, Zhu Q, Xu TP,Zou YF, Xie M, Sun M, Xia R and Lu KH: Long non-coding RNA MVIH indicates a poor prognosis for non-small cell lung cancer and promotes cell proliferation and invasion. Tumour Biol 35: 7587-7594, 2014.

51. Yang F, Huo XS, Yuan SX, Zhang L, Zhou WP, Wang F and Sun SH: Repression of the long noncoding RNA-LET by histone deacetylase 3 contributes to hypoxia-mediated metastasis. Mol Cell 49: 1083-1096, 2013.

52. Sun C, Li S, Zhang F, Xi Y, Wang L, Bi Y and Li D: Long non-coding RNA NEAT1 promotes non-small cell lung cancer progression through regulation of miR-377-3p-E2F3 pathway. Oncotarget: Jun 16, 2016 (Epub ahead of print).

53. Naganuma $T$ and Hirose $T$ : Paraspeckle formation during the biogenesis of long non-coding RNAs. RNA Biol 10: 456-461, 2013.

54. Tani $\mathrm{H}$, Torimura $\mathrm{M}$ and Akimitsu N: The RNA degradation pathway regulates the function of GAS5 a non-coding RNA in mammalian cells. PLoS One 8: e55684, 2013.

55. Ma MZ, Chu BF, Zhang Y, Weng MZ, Qin YY, Gong W and Quan ZW: Long non-coding RNA CCAT1 promotes gallbladder cancer development via negative modulation of miRNA-218-5p. Cell Death Dis 6: e1583-e1583, 2015.

56. Xiong X, Ren HZ, Li MH, Mei JH, Wen JF and Zheng CL: Down-regulated miRNA-214 induces a cell cycle G1 arrest in gastric cancer cells by up-regulating the PTEN protein. Pathol Oncol Res 17: 931-937, 2011.

57. Qiang R, Wang F, Shi LY, Liu M, Chen S, Wan HY, Li YX, Li X, Gao SY and Sun BC: Plexin-B1 is a target of miR-214 in cervical cancer and promotes the growth and invasion of HeLa cells. Int J Biochem Cell Biol 43: 632-641, 2011. 